\title{
ZebraShare: A new venue for rapid dissemination of zebrafish mutant data
}

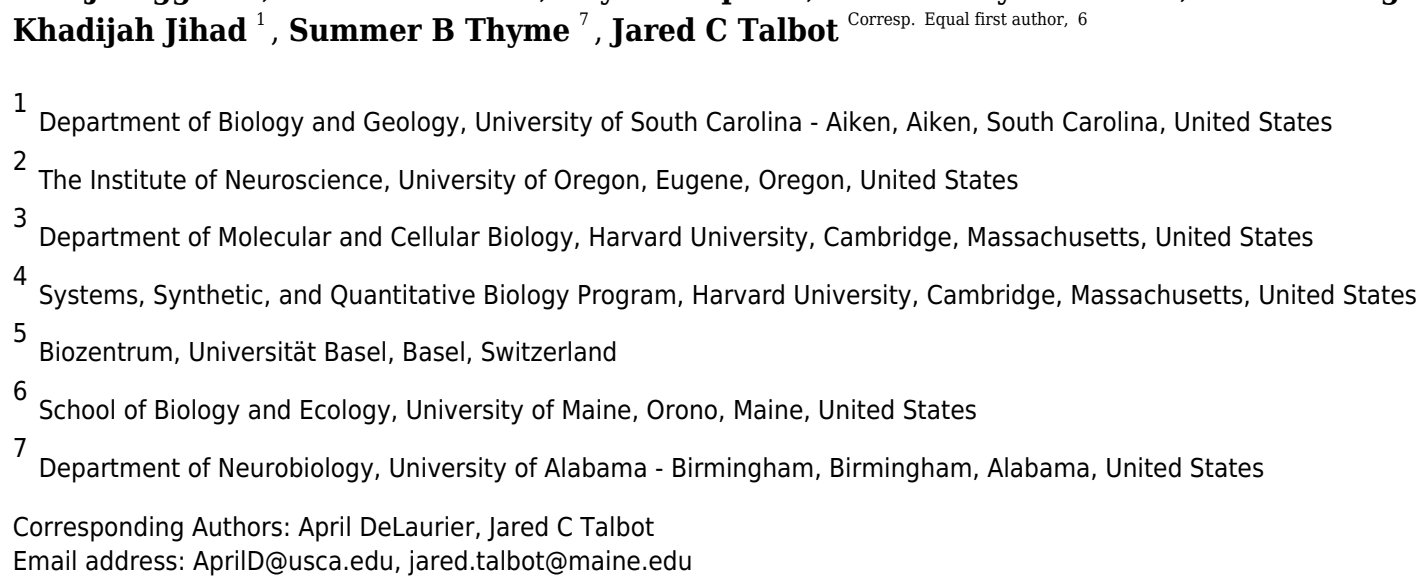

Background. In the past decade, the zebrafish community has widely embraced targeted mutagenesis technologies, resulting in an abundance of mutant lines. While many lines have proven to be useful for investigating gene function, many have also shown no apparent phenotype, or phenotypes not of interest to the originating lab. In order for labs to document and share information about these lines, we have created ZebraShare as a new resource offered within ZFIN. Methods. ZebraShare involves a form-based submission process generated by ZFIN. The ZebraShare interface ( https://zfin.org/action/ZebraShare ) can be accessed on ZFIN under "Submit Data". Users download the Submission Workbook and complete the required fields, then submit the completed workbook with associated images and captions, generating a new ZFIN publication record. ZFIN curators add the submitted phenotype and mutant information to the ZFIN database, provide mapping information about mutations, and cross reference this information across the appropriate ZFIN databases. We present here examples of ZebraShare submissions, including phf21aa, kdmla, ctnnd1, snu13a, and snu13b mutant lines. Results. Users can find ZebraShare submissions by searching ZFIN for specific alleles or line designations, just as for alleles submitted through the normal process. We present several potential examples of submission types to ZebraShare including aphenotypic mutants, mildly phenotypic, and early lethal mutants. Mutants for kdmla show no apparent skeletal phenotype, and phf2laa mutants show only a mild skeletal phenotype, yet these genes have specific human disease relevance and therefore may be useful for further studies. The n120-catenin encoding gene, ctnnd1, was knocked out to
Peer) reviewing PDF ( $2020: 08: 52244: 1: 1: N E W 7$ Jan 2021) 
investigate a potential role in brain development or function. The homozygous ctnnd1 mutant disintegrates during early somitogenesis and the heterozygote has localized defects, revealing vital roles in early development. Two snu13 genes were knocked out to investigate a role in muscle formation. The snu13a;snu13b double mutant has an early embryonic lethal phenotype, potentially related to a proposed role in the core splicing complex. In each example, the mutants submitted to ZebraShare display phenotypes that are not ideally suited to their originating lab's project directions but may be of great relevance to other researchers. Conclusion. ZebraShare provides an opportunity for researchers to directly share information about mutant lines within ZFIN, which is widely used by the community as a central database of information about zebrafish lines. Submissions of alleles with a-phenotypic or unexpected phenotypes is encouraged to promote collaborations, disseminate lines, reduce redundancy of effort and to promote efficient use of time and resources. We anticipate that as submissions to ZebraShare increase, they will help build an ultimately more complete picture of zebrafish genetics and development. 


\section{ZebraShare: A new venue for rapid dissemination of}

\section{2 zebrafish mutant data}

3

4

22

23

24

25

26

27

28

29

30

31

32

33

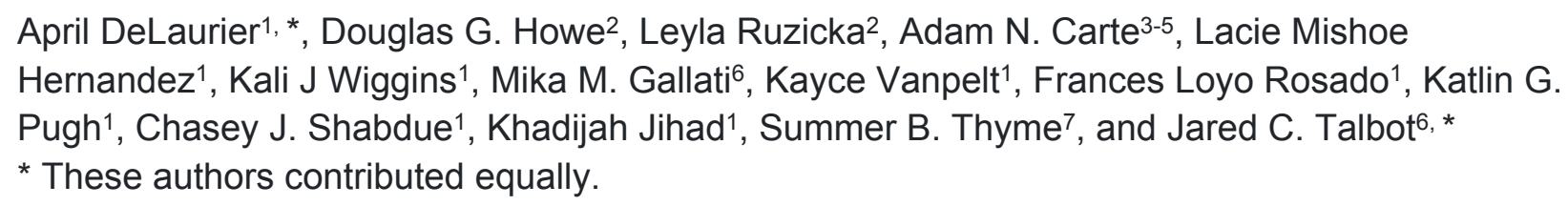

1) Department of Biology and Geology, University of South Carolina Aiken, Aiken, SC, USA

2) The Institute of Neuroscience, University of Oregon, Eugene, OR, USA.

3) Department of Molecular and Cellular Biology, Harvard University, Cambridge, MA, USA

4) Systems, Synthetic, and Quantitative Biology Program, Harvard University, Cambridge, MA, USA

5) Biozentrum, Universität Basel, Basel, Switzerland

6) School of Biology and Ecology, University of Maine, Orono, ME, USA

7) Department of Neurobiology, University of Alabama - Birmingham, Birmingham, Alabama, United States

Corresponding Author:

Jared C. Talbot

5735 Hitchner Hall Room 303, Orono, ME, 04469, USA

Email address: jared.talbot@maine.edu

Co-corresponding Author:

April DeLaurier

471 University Parkway, Aiken, SC 29801

Email address: aprild@usca.edu 


\section{Abstract}

36 Background. In the past decade, the zebrafish community has widely embraced targeted mutagenesis technologies, resulting in an abundance of mutant lines. While many lines have proven to be useful for investigating gene function, many have also shown no apparent phenotype, or phenotypes not of interest to the originating lab. In order for labs to document and share information about these lines, we have created ZebraShare as a new resource offered within ZFIN.

Methods. ZebraShare involves a form-based submission process generated by ZFIN. The ZebraShare interface (https://zfin.org/action/ZebraShare) can be accessed on ZFIN under "Submit Data". Users download the Submission Workbook and complete the required fields, then submit the completed workbook with associated images and captions, generating a new ZFIN publication record. ZFIN curators add the submitted phenotype and mutant information to the ZFIN database, provide mapping information about mutations, and cross reference this information across the appropriate ZFIN databases. We present here examples of ZebraShare submissions, including phf2laa, kdmla, ctnnd1, snu13a, and snu13b mutant lines.

Results. Users can find ZebraShare submissions by searching ZFIN for specific alleles or line designations, just as for alleles submitted through the normal process. We present several potential examples of submission types to ZebraShare including a-phenotypic mutants, mildly phenotypic, and early lethal mutants. Mutants for $k d m l a$ show no apparent skeletal phenotype, and phf 2 la mutants show only a mild skeletal phenotype, yet these genes have specific human disease relevance and therefore may be useful for further studies. The p120-catenin encoding gene, ctnndl, was knocked out to investigate a potential role in brain development or function. The homozygous ctnnd 1 mutant disintegrates during early somitogenesis and the heterozygote has localized defects, revealing vital roles in early development. Two snu13 genes were knocked out to investigate a role in muscle formation. The snu13a;snul3b double mutant has an early embryonic lethal phenotype, potentially related to a proposed role in the core splicing complex. In each example, the mutants submitted to ZebraShare display phenotypes that are not ideally suited to their originating lab's project directions but may be of great relevance to other researchers.

64 Conclusion. ZebraShare provides an opportunity for researchers to directly share information about mutant lines within ZFIN, which is widely used by the community as a central database of information about zebrafish lines. Submissions of alleles with a-phenotypic or unexpected phenotypes is encouraged to promote collaborations, disseminate lines, reduce redundancy of effort and to promote efficient use of time and resources. We anticipate that as submissions to ZebraShare increase, they will help build an ultimately more complete picture of zebrafish genetics and development.

\section{Introduction}

73 In the last decade use of reverse genetics has become a standard approach to investigate gene 
75

76

77

78

79

80

81

82

83

84

85

86

87

88

89

90

91

92

93

94

95

96

97

98

99

100

101

102

103

104

105

106

107

108

109

110

111

112

113

114

possible to direct mutagenesis in zebrafish, which became easier with TALENS and then even simpler with CRISPR-Cas9 technology (Rafferty \& Quinn, 2018). The simplicity of targeted mutagenesis in zebrafish has led to mass production of knockout lines targeting genes and genetic pathways of interest. Some mutants show phenotypes that have led to impactful publications, but it is apparent that many more mutants have no phenotypic defect (aphenotypic), subtle phenotypes, or phenotypes in tissues that are not in the research focus of the originating lab (Kok et al., 2015; Stainier, Kontarakis \& Rossi, 2015). Although mutants with unexpected phenotypes may sometimes not be pursued by the originating lab, information about these lines is still critically relevant to the broader research community. Failure to disseminate these findings and alleles will ultimately lead to redundant efforts, lost time, and wasted resources. To facilitate information distribution about zebrafish lines, we have integrated a new feature into the Zebrafish Information Network (ZFIN) called "ZebraShare”. In ZebraShare, users submit an abstract, knockout sequences, validation steps, and phenotypic information directly to ZFIN. Submissions are curated by ZFIN staff into the ZebraShare database for public viewing. Future information or edits can be added to the submission over time, which may include further descriptions of phenotypes or other relevant information about lines. We anticipate that ZebraShare will help zebrafish researchers engage in optimized use of their reverse genetics mutants by avoiding redundancy, sharing phenotypes that would be otherwise lost, and forging collaborations for future research. Here, we describe the ZebraShare feature of ZFIN. We begin by describing the submission process and features included which ensure that data quality can quickly be assessed by ZFIN users. Then, we provide four differing examples of submissions and for each example provide the rationale for constructing the mutant and why the resulting phenotypes lead to ZebraShare submission. Finally, we discuss the implications of this new sharing system.

\section{Materials \& Methods}

Animal stocks and husbandry: We raised and housed zebrafish in standard conditions (Westerfield, 2007) and collected embryos by natural spawning of adult fish, with embryo staging as described (Kimmel et al., 1995). All zebrafish experimentation was conducted as approved by Institutional Animal Care and Use Committees at the University of Maine (approval number A2019_10_01), The Ohio State University (approval number 2012A00000113), the University of Alabama at Birmingham (approval number 21744), Harvard University (approval number 25-08), the University of South Carolina (approval number 2485-101478-031720) and the University of South Carolina Aiken (010317-BIO-01).

Oligonucleotides: Table 1 lists the oligonucleotides used in this study during mutant construction and genotyping.

phf21aa mutant construction: For phf2laa mutant (phf2laa aik4) construction, wild-type AB embryos were co-injected with $3 \mathrm{nl}$ of a mixture containing guide RNA targeting exon 6 (ENSDART00000173629.2) ( 160 ng/ $\mu$ l) along with mRNA encoding nuclear-localized Cas9 ( $160 \mathrm{ng} / \mu \mathrm{l})$. Nuclear-localized Cas9 mRNA was synthesized from pCS2-nCas9n (Addgene), 
115 linearized with NotI-HF (New England Biolabs), column purified (Zyppy Plasmid Miniprep kit; 116 Zymo Research), and mRNA was synthesized (mMessenge mMachine SP6 kit; Thermo

117 Fisher). Mutagenesis efficiency was detected in groups of F0 embryos (5 pooled x 3 replicates)

118 using T7 endonuclease (New England Biolabs) digest of PCR fragments flanking the gRNA

119 target site (PCR product $=995$ base-pairs (bp), digestion products are approximately 720 and

$120275 \mathrm{bp}$ ). DNA from potential individual mutants was Sanger sequenced to establish a line with a

$1217 \mathrm{bp}$ deletion at the gRNA target site in exon $6\left(p h f 21 a a^{a i k 4}\right)$. This mutation results in a

122 frameshift mutation producing extensive missense mutations and a premature stop codon

123 (GenBank accession numbers: wild type MW438986, mutant MW438985). Genotyping of

124 subsequent individual phf21aa aik fish utilized primers flanking the indel site. PCR amplification

125 results in a $641 \mathrm{bp}$ product for wild-type DNA and a $634 \mathrm{bp}$ product for mutant DNA. PCR

126 products are run on a $2.5 \%$ agarose gel to resolve bands (wild type $=641 \mathrm{bp}$, mutant $=634 \mathrm{bp}$,

127 heterozygotes $=641+634$ bp bands).

$128 \boldsymbol{k d m} 1 \boldsymbol{a}$ mutant construction: For $k d m l a$ mutant $\left(k d m l a^{a i k 5}\right)$ construction, wild-type $\mathrm{AB}$

129 embryos were co-injected with guide RNA targeting exon 1 (ENSDART00000180532.1) ( 200

$130 \mathrm{ng} / \mu \mathrm{l})$ along with mRNA encoding nuclear-localized Cas9 $(\sim 160 \mathrm{ng} / \mu \mathrm{l})$. Nuclear-localized Cas9

131 mRNA was synthesized and injected as described above for phf2laa. Mutagenesis efficiency

132 was detected in groups of F0 embryos (5 pooled x 3 replicates) using T7 endonuclease digest of

133 PCR fragments flanking the guide RNA target site (PCR product $=299 \mathrm{bp}$, digestion products

134 are approximately 228 and $71 \mathrm{bp}$ ), as described for phf21aa. cDNA from individual potential

135 mutants was Sanger sequenced to establish a line with a $14 \mathrm{bp}$ deletion at the guide RNA target

136 site in exon $1\left(\mathrm{kdm} / \mathrm{a}^{a i k 5}\right)$. This mutation is predicted to result in a frameshift producing extensive

137 missense and a premature stop codon. Genotyping of subsequent individual $k d m l a^{a i k s}$ fish

138 utilizes the same T7 primers flanking the indel site. PCR amplification results in a $299 \mathrm{bp}$

139 product for wild-type DNA and a 285 bp product for mutant DNA. PCR products are run on a

$1402.5 \%$ agarose gel to resolve bands (wild type $=299 \mathrm{bp}$, mutant $=285 \mathrm{bp}$, heterozygotes $=299+$

141285 bp bands).

142 ctnnd1 mutant construction: The ctnnd1 mutant (ctnnd $1^{\text {uab302 }}$ ) was constructed by injection of

143 three guide RNAs ( $>50 \mathrm{ng} / \mu \mathrm{l}$ each) and purified Cas9 protein $(25 \mu \mathrm{M})$ into wild-type EKW

144 embryos. The first two nucleotides of every guide were changed to 5'-GG-3' for high-yield

145 synthesis with T7 polymerase. Heterozygous carriers were initially identified on pools with

146 MiSeq sequencing and later confirmed with Sanger sequencing. PCR of this 31 bp deletion

147 results in a $242 \mathrm{bp}$ product for wild-type DNA and a $211 \mathrm{bp}$ product for mutant DNA. PCR

148 products were separated with standard agarose gel electrophoresis on $4 \%$ gels. The injected (F0)

149 fish were raised to adulthood and F1 carriers confirmed by sequencing were outcrossed to wild-

150 type EKW fish.

151 snu13a and snu13b mutant construction: The snu13a and snu13b mutants were constructed

152 following described methods (Talbot \& Amacher, 2014). An injection mix containing $38 \mathrm{ng} / \mu \mathrm{l}$

153 of guide RNA targeting snul $3 a$ and $83 \mathrm{ng} / \mu 1$ of mRNA encoding nuclear localized Cas9 (Jao,

154 Wente \& Chen, 2013) was injected into AB fish. For snul3b, the injection was similar except the

155 snul $3 b$ guide RNA had a concentration of $37 \mathrm{ng} / \mu 1$. To prepare the Cas 9 mRNA we synthesized

156 from pCS2-nCas9n (Jao, Wente \& Chen, 2013) after linearization with NotI (New England

Peer) reviewing PDF | (2020:08:52244:1:1:NEW 7 Jan 2021) 
157 Biolabs) using a mMessage mMachine kit (Thermo Fisher) and purified using a NucleoSpin II

158

159

160

161

162

163

164

165

166

167

168

169

170

171

172

173

174

175

176

177

178

179

180

181

182

183

184

185

186

187

188

189

190

191

192

193

194

195

196

RNA cleanup kit (Machery-Nagel). Mutagenesis efficiency was determined using High Resolution Melt Analysis (HRMA) (Talbot and Amacher 2014; Dahlem et al., 2012). These F1 carriers were outcrossed and identified by testing 16 embryos per clutch using HRMA. HRMA was again used to pre-screen $\mathrm{F} 1$ heterozygote carriers, which were sequenced using primers specific to snu $13 a$ and snu $13 b$. Sequence analysis was performed on individual snul $3 a^{-/} ;$snu $13 b^{-}$ 1- embryos.

Histological staining and imaging of skeletal tissue: Larval skeletal samples ( $p h f 21 a a$ and $k d m l a$ ) were prepared and stained using Alcian Blue and Alizarin Red dyes as described (Walker \& Kimmel, 2007; DeLaurier, Alvarez \& Wiggins, 2019). Samples were flat-mounted and imaged using an Olympus BX41 compound microscope and Olympus cellSens Standard software (version 1.16).

DAPI-stained embryos: $c$ tnnd 1 embryos were left in the chorion and fixed overnight in $4 \%$ formaldehyde in PBS. Embryos were then washed $4 \times 5$ minutes in PBS, incubated in DAPI for 30 minutes, and washed $2 \times 5$ minutes in PBS before being mounted in a droplet of $1 \%$ lowmelting agarose in PBS on a 35mm MatTek dish with a No. 1.5 coverslip bottom. Imaging was performed on a Zeiss LSM700 inverted laser scanning confocal microscope with a PlanApochromat $10 \mathrm{X} / 0.45$ air objective using $5 \mu \mathrm{m}$ slices. Maximum intensity projections were produced from acquired z-stacks in Fiji (Schindelin et al., 2012), and images were scaled to maximize for visibility.

Live imaging snu13 mutants: Zebrafish embryos from in-cross of snu13a $a^{o z 24 /+}$;snu13boz91/+ were monitored through their first 12 hours of development, and then imaged using a Leica DMC5400 camera mounted on a Leica MZ10F microscope at 24 hours post-fertilization (hpf).

Live imaging ctnnd1 mutants: ctnnd 1 embryos were photographed at approximately the 6somite stage using identical magnification and lighting settings across embryos on a Zeiss AXIO Zoom V16 microscope fitted with a PlanNeoFluar Z 1x/0.25 objective and Axiocam 503 color camera. Embryo photographs were color-balanced using the BIOP SimpleColorBalance plugin in ImageJ (Schindelin et al., 2012). The time-lapse recording of developing ctnndl embryos was made from approximately the 4-6 somite stage to the 12-14 somite stage using the "TIMELAPSE" function on an iPhone 8 mounted to a Zeiss Stemi 2000 stereo microscope with a Gosky Universal Cell Phone Adapter Mount.

\section{Results}

ZebraShare implementation: ZebraShare implements several new features into existing ZFIN functionalities. A ZebraShare landing page, linked from the "Submit Data" button on the ZFIN home page, contains a summary of the project and links to the workbook and submission page (Figure 1). ZebraShare is designed to fit into ZFIN's existing publication acquisition infrastructure, nomenclature, and curation workflows. When completing the ZebraShare Workbook, researchers are asked to define precise coordinates of the mutation so the alleles can be described accurately in ZFIN (Figure 2) and to provide information relevant to the mutant

Peerj reviewing PDF | (2020:08:52244:1:1:NEW 7 Jan 2021) 
197 phenotypes. When uploading this workbook, authors have an opportunity to enter an abstract

198

199

200

201

202

203

204

205

206

207

208

209

210

211

212

213

214

215

216

217

218

219

220

221

222

223

224

225

226

227

228

229

230

231

232

233

234

235

236

describing their allelic and phenotypic characterization (Figure 3, Table 2). This abstract is linked to the workbook and any images and captions included in the submission. Upon creation, ZebraShare submissions are automatically assigned to the ZFIN nomenclature coordinator. The coordinator vets nomenclature, consults authors if needed, and after adding alleles to ZFIN with correct nomenclature, assigns the paper to the high-priority ZebraShare curation queue. Curators complete curation by adding the remaining details for mutants to the publication and inform the authors that their submission has been curated. Once a ZebraShare submission is completed, the mutant alleles and phenotypes can be searched for just like the ZFIN entries curated from papers (Van Slyke et al., 2018).

Ensuring validated mutant information: ZebraShare provides researchers an opportunity to detail their own validation steps in the submission workbook, which will be listed on the allele page. First, researchers enter detailed descriptions of the mutation using a written description, sequence alignment, and predicted effect on transcript and protein. Then, researchers specify whether the transcript changes are determined directly from cDNA sequencing or inferred from genomic sequences. A field is also provided where researchers can specify whether nonsensemediated decay (NMD) has been assayed, because of the growing concern that compensation may occur in alleles that induce NMD (Rossi et al., 2015; El-Brolosy et al., 2019). Researchers can state whether mutations have been examined in homozygous embryos from heterozygous parents, or whether maternal-zygotic knockouts have been examined. Information about maternal-zygotic outcomes may be particularly important for mutations showing little or no phenotype in the offspring of heterozygous crosses. While validation experiments are not required for submission to ZebraShare, these fields are included to provide researchers an opportunity to communicate this information if desired. Because mutant validation may be improved after submission, and line availability may change, the following fields remain editable by submitting researchers and their designees after submission: 'Functional Consequence,' 'Adult Viable,' 'Maternal Zygosity Examined,' 'NMD Apparent,' 'Other Line Information,' and 'Available'. Only the submitting researcher and other researchers designated at the time of mutant allele submission are able to edit these fields.

\section{Example 1, phf21aa knockout shows a mild craniofacial skeletal phenotype: $p h f 21 a a$} homozygous mutants develop normally, have no obvious external abnormalities, and are viable, fertile adults. A slight medial rotation of the ceratohyal cartilage was detected in whole mount mutant specimens at $7 \mathrm{dpf}$ (Figure 3C) in maternal-zygotic mutants (7/20) not detected in heterozygote offspring (35/35). Flat mount of pharyngeal skeletons reveals no ceratohyal patterning defect in mutants compared to wild-type siblings (Figure 3C), suggesting the rotation defect may be the result of a connective tissue defect not apparent in skeletal preparations. Loss of PHF21A is associated with Potocki-Shaffer Syndrome (PSS) in humans and is associated with craniofacial and neurological complications (Kim et al., 2012, 2019). Thus, although this mutant

Peerj reviewing PDF | (2020:08:52244:1:1:NEW 7 Jan 2021) 
237

238

239

240

241

242

243

244

245

246

247

248

249

250

251

252

253

254

255

256

257

258

259

260

261

262

263

264

265

266

267

268

269

270

271

272

273

274

275

276

did not have a skeletal phenotype of interest to the originating lab, the phf 2 laa line may have other important uses as a disease model, so information about this line was provide to ZebraShare (Mishoe L.N. and DeLaurier, 2020). Researchers with interest in pursuing a zebrafish model for PSS may wish to investigate the origin of the anatomical defect in phf2laa mutants, in double mutants for the zebrafish co-ortholog for phf21aa, phf21ab, or in combination with mutants for other interacting factors (i.e. kdm la, ZNF 198/zmym2, ZNF261/zmym3) (Hakimi et al., 2003; Shi et al., 2004; Lan et al., 2007; Kim et al., 2012, 2019).

Example 2, $\boldsymbol{k d m} 1 \boldsymbol{a}$ mutants have no overt skeletal phenotype: $k d m l a$ (zygotic and maternalzygotic) homozygous mutants develop normally, have no obvious external abnormalities, and are viable, fertile adults. Analysis of craniofacial skeletal patterning in $k d m l a$ maternal-zygotic mutants at stages between 4-8 dpf (Figure 4) reveals no specific defects in cartilage or bone $(21 / 23)$ compared to $k d m l a$ wild-type (18/18) $k d m l a$ larvae. Because the $k d m l a$ mutant was aphenotypic, the originating lab chose not to pursue it further. To prevent others from spending redundant effort generating the same line, information about this mutant was provided submitted to ZebraShare (DeLaurier et al., 2020). KDM1A functions as a histone demethylase transcriptional corepressor in a multi-protein HDAC1/2/CoREST-containing complex (Hakimi et al., 2003; Shi et al., 2004). Humans with mutations in $K D M 1 A$ are reported to have craniofacial defects including cleft palate and developmental delay (Tunovic et al., 2014; Chong et al., 2016), these clinical features are also found in Kabuki syndrome. In one study (Turnovic et al., 2014), clinical features are hypothesized to result from the combined effect of mutations in KDM1A and ANKRD11 (Ankrin Repeating Domain-Containing protein 11), the latter of which is associated with KBG syndrome involving craniofacial phenotypes. PHF21A and KDM1A interact, where binding of PHF21A to histones is required for the repressive activity of KDM1A (Lan et al., 2007; Kim et al., 2012). Given that both $K D M 1 A$ and $P H F 21 A$ underlie craniofacial defects in humans, zebrafish mutant models for these genes may be of potential interest to labs studying human syndromes such as Kabuki, KBG, and PSS-type syndromes.

Example 3, ctnnd1 mutants disintegrate by 24 hpf: The ctnnd1 gene was knocked out because it is within a locus associated with neuropsychiatric disorders (Schizophrenia Working Group of the Psychiatric Genomics Consortium, 2014) and the related gene CTNND2 has been linked to autism (Turner et al., 2015). Prior analysis using a ctnnd1 morpholino (MO) noted embryonic disassociation at high doses and bent tails at lower doses (Hsu et al., 2012); however, without mutant validation these ctnnd1-MO phenotypes are difficult to distinguish from non-specific morpholino toxicity (Stainier et al., 2017; Robu et al., 2007; Bedell et al., 2011). Consistent with a requirement for ctnndl in embryonic viability, in-cross of ctnndl heterozygotes yields no homozygous mutants $6 \mathrm{dpf}(\mathrm{N}=44$ wild type, 56 het, 0 mutant, Chi Square analysis $\mathrm{P}<0.0001)$. Subsequent analysis revealed that the ctnnd 1 homozygotes proceed through cleavage stages and gastrulate but typically die between the 4 and 12 somite stages (Figure 5A, B). Embryonic death occurs via cellular disassociation (Figure 5C), initiating at the head or the tailbud

Peer) reviewing PDF | (2020:08:52244:1:1:NEW 7 Jan 2021) 
277 (Supplementary Movie 1). In ctnndl heterozygotes, small clumps of cells briefly appear on the 278 embryo's dorsal surface during early somitogenesis stages, typically over the mid- or hindbrain 279 regions (Figure 5D-F). Given that the homozygote fully disassociates, the heterozygote's small 280 clumps of ectopic cells may represent localized points of disassociation. Genotyping at $12 \mathrm{hpf}$ 281 confirms that 24/24 "dying" embryos are homozygous mutant, 25/25 embryos with ectopic cells 282 are heterozygous, and 23/23 healthy embryos are wild type (Chi Square analysis $\mathrm{P}<0.001$ ). 283 Because early lethality precludes analysis of neural phenotypes, information about the $c$ tnnd 1 284 mutants was deposited in ZebraShare (Thyme and Carte 2020). Consistent with the zebrafish 285 findings, the p120-catenin protein encoded by ctnnd 1 has several known roles in early 286 287 288 development and murine loss-of-function models are embryonic lethal when homozygous (Hernández-Martínez, Ramkumar \& Anderson, 2019). The mouse Ctnndl neural crest knockout line shows cleft palate when heterozygous and consistent defects are seen in humans heterozygous for CTNND1 truncation alleles (Alharatani et al., 2020). Ctnnd1 is involved in cadherin stabilization, WNT signaling during gastrulation and epithelial-to-mesenchymal transitions, and suppression of the RhoA-ROCK-myosin pathway (Pieters et al., 2016; Yu et al., 2016; Hernández-Martínez, Ramkumar \& Anderson, 2019). It is unclear which of these functions are the direct cause of the zebrafish ctnnd 1 defects and researchers interested in any of these mechanisms and/or in CTNND1-related human disease may find this mutant useful.

Example 4, snu13a;snu13b double mutants arrest during somitogenesis: Previous analysis of Snul3 gene function in flies and zebrafish supported a specific role in muscle formation (Johnson et al., 2013; Williams et al., 2015). To further test this role, the two zebrafish genes, snul $3 a$ and snul $3 b$, were knocked out. DNA sequencing of the resulting mutants indicates that they both cause frameshift and premature stop codons. The snu13a $a^{-/}$and $s n u 13 b^{-/}$single mutants are both overtly indistinguishable from wild-type siblings (not shown). Embryos homozygous for the two mutations (snul $3 a^{-/} ;$snul $3 b^{-/}$) appear normal until $10 \mathrm{hpf}$ but their development ceases to progress by $12 \mathrm{hpf}$, after which the cells linger in place and typically become necrotic by 24 hpf (Figure 6). Some of the fish with this severe phenotype are homozygotically mutant for snul $3 b$ but only heterozygous for snu $13 a\left(\right.$ snul $3 a^{+/-} ;$snul $3 b^{-/}$). These snul $3 a^{+/} ;$snul $3 b^{-/-}$fish are often indistinguishable from the double mutant shown in figure 6, but are sometimes indistinguishable from wild-type siblings ( 40 with wild-type phenotype were genotyped: 0 are

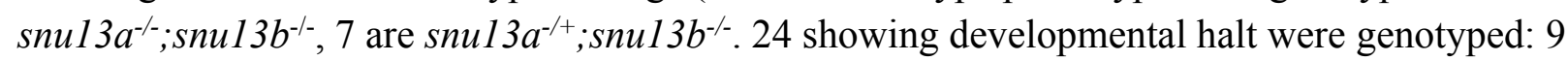
are snu13a $a^{-/} ;$snu $13 b^{-/}, 16$ are snu1 $3 a^{+/} ;$snu1 $3 b^{-/}$, Chi Square analysis $\left.\mathrm{P}<0.0001\right)$. These findings reveal that embryonic development can only sometimes proceed through somitogenesis stages when snul3 function is strongly reduced (snu13a $a^{+-} ;$snu $\left.13 b^{-/}\right)$and cannot proceed in the absence of snul3 gene function ( $\left(\right.$ nu1 $3 a^{-/} ;$;nu13 $\left.b^{-/}\right)$. A severe developmental halt is likely explained by a requirement for Snu13 protein in assembly of the core spliceosome (Stevens et al., 2001; Dobbyn \& O'Keefe, 2004; Oruganti, Zhang \& Li, 2005; Rothé et al., 2014; Diouf et al., 2018). These mutant phenotypes demonstrate that snu13a \& snu13b gene function is essential to organismal viability and development past early embryogenesis. This severe embryonic phenotype impeded 
317 further investigation of muscle formation; however, these lines may be valuable to the broader 318 research community, so information about the snu $3 a$ and snul $3 b$ mutants was submitted to 319 ZFIN via ZebraShare (Gallati and Talbot 2020). The mutants may be of interest to researchers 320 investigating the core spliceosome, or as a comparison group for investigation of alternative 321 splicing pathways. These mutants may also be useful to labs studying the maternal to zygotic 322 transition because both snul $3 a$ and snul $3 b$ are expressed prior to zygotic genome activation 323 (Papatheodorou et al., 2018).

324

325 Discussion

326 Currently, there is no comprehensive zebrafish mutant library that parallels those available for

327

328

329

330

331

332

333

334

335

336

337

338

339

340

341

342

343

344

345

346

347

348

349

350

351

352

353

354

355

yeast, drosophila, and worms (Winzeler et al., 1999; Thurmond et al., 2019; Harris et al., 2020). While large scale mutagenesis projects are being undertaken, such as the Sanger Targeting Induced Local Lesions in Genomes (TILLING) screen (Kettleborough et al., 2013), in most examples these mutant collections exist only in untested frozen sperm that carry many mutations in other genes. ZebraShare is intended to expand the ZFIN mutant collection by encouraging labs to publicize characterized alleles that lack an obvious route to traditional publication (Figure 7A) and is a suitable destination for archiving information about alleles that labs may not plan to pursue.

Lines submitted to ZebraShare are publicly visible, and the abstracts can be cited, but the submissions may not include some information vital to journal publication, such as details about mutant construction. For instance, in this manuscript we cite abstracts of ZebraShare submissions but also include details about mutant construction in our methods section. To include these details, we needed to collect and coordinate information from each originating lab. Likewise, if other researchers would like to incorporate ZebraShare data into their own traditional publications, they should contact the lab which originated the mutant line. Thus, the ZebraShare system is intended to facilitate dissemination of unpublished mutant information and collaboration formation, to complement and enhance traditional routes of publication. In this paper, we provide examples of mutants that we publicized using ZebraShare, such as aphenotypic alleles ( $k d m l a)$, mildly phenotypic ( $p h f 2 l a a)$, and those with severe early defects (snu13a;snul3b and ctnnd1). The diversity in described early lethal phenotypes, snu13a;snu13b arrests and ctnnd 1 disintegrates, highlight the reality that different processes can underlie embryonic death. The observation that some snu $13 a^{+/} ;$snu $13 b^{-/}$fish can proceed through somitogenesis while others cannot underscores variation often observed in mutant phenotypes, which is potentially influenced by genetic or environmental modifiers. New discoveries may stimulate new interest in submitted lines. While there was no clear disease connection when the ctnndl homozygous lethal phenotypes were submitted to ZebraShare, subsequent analysis of the heterozygote reveals a more specific cellular disassociation at the embryo's dorsal edge, which could potentially be related to neural crest defects recently reported in humans with CTNNDI gene variants (Alharatani et al., 2020). Finally, ZebraShare may also provide information about

Peer) reviewing PDF | (2020:08:52244:1:1:NEW 7 Jan 2021) 
356

357

358

359

360

361

362

363

364

365

366

367

368

369

370

371

372

373

374

375

376

377

378

379

380

381

382

383

384

385

386

387

388

389

390

391

392

393

394

395

alleles which reproduce phenotypes found already in publication and offers a way to quickly share phenotypes that verify or contradict the literature.

We generated ZebraShare to help researchers disseminate information about mutants which have no clear path to standard journal publication, including mutants that have no overt phenotypic defect. When mutants lack a desired phenotype, researchers may dismiss the finding because of compensatory mechanisms like gene redundancy, transcriptional compensation, unexpected splice variants, and maternal contributions (Ciruna et al., 2002; Rossi et al., 2015; Anderson et al., 2017; El-Brolosy et al., 2019). While these compensatory mechanisms sometimes do explain a lack of phenotype, the absence of phenotypic defect does not constitute evidence that one of these mutation-bypassing mechanisms are being used. In many cases a-phenotypic mutants provide genuine insights into gene function. We strongly believe that the dissemination of information about such unexpected phenotypes is necessary to reduce duplicate effort and to foster honest, open discussion about the necessity, redundancy, and interactions between individual genes in zebrafish.

ZebraShare complements other rapid mutant dissemination platforms (Figure 7B). For instance, CRISPRz allows researchers to share information about CRISPR guide RNAs but does not describe alleles generated nor mutant phenotypes (Varshney et al., 2016). Several researchers have put forward their own websites for describing mutants and transgenes (e.g., https://kawakami.lab.nig.ac.jp/), although individual lab websites may not be completely integrated into ZFIN. ZebraShare is conceptually similar to the ZFIN antibody and protocol wikis, which have provided valuable information to the zebrafish community for many years (Bradford et al., 2011; Howe et al., 2016). Unlike these wiki-style submissions to ZFIN, ZebraShare submissions are manually curated by ZFIN staff and are directly integrated into the database itself rather than as a separate wiki. ZFIN already accepts large datasets of lesscharacterized mutants and other direct submissions (Howe et al., 2016), which has been used by the Sanger TILLING project and several North American TILLING projects (Moens et al., 2008; Kettleborough et al., 2013 among others); however, ZebraShare is the first mechanism for labs to disseminate detailed information about individual mutations and phenotypes on ZFIN. Thus, ZebraShare fills a key niche by enabling individual labs to directly submit allelic and phenotypic information for up to a few mutants in ZFIN (Figure 7B).

In the long term, ZebraShare will serve to facilitate reporting from our community's collective project and enable the field to report about the function of more genes than can be communicated exclusively through traditional publications. We anticipate that researchers will contribute information about multiple alleles within individual genes as this information becomes available. Different lesions for single genes may have slightly different effects on RNA/protein (e.g. premature stop vs., splice error, vs. deletion of functional domains). Thus, deposition of information about multiple alleles will be extremely useful as our community discerns which mutation types have the strongest effects on development, and may influence the dialogue about discrepancies between morpholino and mutant data (Kok et al., 2015; Stainier, Kontarakis \& Rossi, 2015; El-Brolosy et al., 2019; Tessadori et al., 2020). The ease of sharing will encourage 
396

397

398

399

400

401

402

403

404

405

406

407

408

409

410

411

412

413

414

415

416

417

418

419

420

421

422

423

424

425

426

427

428

429

430

431

432

433

434

435

examples and insights into how gene redundancy, maternal effect, and other 'obscuring' factors influence phenotypic severity. Furthermore, the simple ZebraShare submission process opens up opportunities for undergraduates, rotation students, and other new scientists to gain the transformative experience of describing and publicizing their findings in a formal and permanent manner with the broader community.

\section{Conclusions}

ZebraShare was conceived and developed in response to a community-wide need for a simple and centralized means to share information about alleles, particularly about a-phenotypic lines (e.g. $k d m l a$ ), or mild or unexpected phenotypes (e.g. phf2laa). Yet, researchers may also want to submit mutants with strong and interesting phenotypes that are outside of the scope of their normal work. For instance, we show a role for ctnnd1 in embryonic integrity, and a role for snul3 genes in development past early somite stages. We anticipate that over time with community submissions growing, ZebraShare will be a valuable resource to facilitate active collaborations on submitted alleles, inform investigators of existing lines, provide preliminary information about potential roles of genes and variants of mutant alleles for those genes, and promote sharing and communication about mutant alleles within the field.

\section{Acknowledgements}

We thank Mark Nilan and the University of Maine zebrafish facility for care of $s n u 13 a^{o z 24}$ and snu $13 b^{o z 91}$ mutants, especially during the 2020 Coronavirus pandemic. We thank Sharon L Amacher (S.L.A.) for supporting construction and early characterization of these snul3 mutants and the Ohio State Rightmire Hall zebrafish facility staff for initial care of these lines. We thank Alexander F. Schier for supporting construction and early characterization of the ctnndl mutants and the Harvard University zebrafish facility staff for initial care of these lines. J.C.T. thanks Sara Loiselle (University of Maine) for comments on this manuscript and Jared Austin (University of Maine) for assistance with snu13a;snu13b genotyping. A.D. thanks Dr. HyungGoo Kim (Augusta University, Hamad Bin Khalifa University) for input and ideas about PHF21A. We also thank the ZFIN development team for creation of the ZebraShare feature in ZFIN.

\section{References}

Alharatani R, Ververi A, Beleza-Meireles A, Ji W, Mis E, Patterson QT, Griffin JN, Bhujel N, Chang CA, Dixit A, Konstantino M, Healy C, Hannan S, Neo N, Cash A, Li D, Bhoj E, Zackai EH, Cleaver R, Baralle D, McEntagart M, Newbury-Ecob R, Scott R, Hurst JA, 
436

437

438

439

440

441

442

443

444

445

446

447

448

449

450

451

452

453

454

455

456

457

458

459

460

461

462

463

464

465

466

467

468

469

470

471

472

473

Au PYB, Hosey MT, Khokha M, Marciano DK, Lakhani SA, Liu KJ. 2020. Novel truncating mutations in CTNND1 cause a dominant craniofacial and cardiac syndrome. Human Molecular Genetics 29:1900-1921. DOI: 10.1093/hmg/ddaa050.

Anderson JL, Mulligan TS, Shen M-C, Wang H, Scahill CM, Tan FJ, Du SJ, Busch-Nentwich EM, Farber SA. 2017. mRNA processing in mutant zebrafish lines generated by chemical and CRISPR-mediated mutagenesis produces unexpected transcripts that escape nonsense-mediated decay. PLOS Genetics 13:e1007105. DOI: 10.1371/journal.pgen.1007105.

Bradford Y, Conlin T, Dunn N, Fashena D, Frazer K, Howe DG, Knight J, Mani P, Martin R, Moxon SAT, Paddock H, Pich C, Ramachandran S, Ruef BJ, Ruzicka L, Bauer Schaper H, Schaper K, Shao X, Singer A, Sprague J, Sprunger B, Van Slyke C, Westerfield M. 2011. ZFIN: enhancements and updates to the zebrafish model organism database. Nucleic Acids Research 39:D822-D829. DOI: 10.1093/nar/gkq1077.

Bedell VM, Westcot SE, Ekker SC. 2011. Lessons from morpholino-based screening in zebrafish. Briefings in Functional Genomics 10:181-188. DOI: 10.1093/bfgp/elr021.

Chong JX, Yu J-H, Lorentzen P, Park KM, Jamal SM, Tabor HK, Rauch A, Saenz MS, Boltshauser E, Patterson KE, Nickerson DA, Bamshad MJ. 2016. Gene discovery for Mendelian conditions via social networking: de novo variants in KDM1A cause developmental delay and distinctive facial features. Genetics in Medicine: Official Journal of the American College of Medical Genetics 18:788-795. DOI: 10.1038/gim.2015.161.

Ciruna B, Weidinger G, Knaut H, Thisse B, Thisse C, Raz E, Schier AF. 2002. Production of maternal-zygotic mutant zebrafish by germ-line replacement. Proceedings of the National Academy of Sciences 99:14919-14924. DOI: 10.1073/pnas.222459999.

Dahlem TJ, Hoshijima K, Jurynec MJ, Gunther D, Starker CG, Locke AS, Weis AM, Voytas DF, Grunwald DJ. 2012. Simple Methods for Generating and Detecting Locus-Specific Mutations Induced with TALENs in the Zebrafish Genome. PLoS Genetics 8:e1002861. DOI: 10.1371/journal.pgen.1002861.

DeLaurier A, Alvarez CL, Wiggins KJ. 2019. hdac4 mediates perichondral ossification and pharyngeal skeleton development in the zebrafish. PeerJ 7:e6167. DOI: 10.7717/peerj.6167.

DeLaurier, A., Wiggins, K., VanPelt, K. 2020. A frameshift mutation in the gene encoding LDLR adaptor protein Ldlrap1a in zebrafish. Zebrashare, ZFIN Abstract: ZDB-PUB180131-10

Diouf B, Lin W, Goktug A, Grace CRR, Waddell MB, Bao J, Shao Y, Heath RJ, Zheng JJ, Shelat AA, Relling MV, Chen T, Evans WE. 2018. Alteration of RNA Splicing by SmallMolecule Inhibitors of the Interaction between NHP2L1 and U4. SLAS DISCOVERY: Advancing Life Sciences R\&D 23:164-173. DOI: 10.1177/2472555217735035. 
474

475

476

477

478

479

480

481

482

483

484

485

486

487

488

489

490

491

492

493

494

495

496

497

498

499

500

501

502

503

504

505

506

507

508

509

510

511

512

Dobbyn HC, O'Keefe RT. 2004. Analysis of Snu13p mutations reveals differential interactions with the U4 snRNA and U3 snoRNA. RNA (New York, N.Y.) 10:308-320. DOI: 10.1261/rna.5970404.

El-Brolosy M, Rossi A, Kontarakis Z, Kuenne C, Guenther S, Fukuda N, Takacs C, Lai S-L, Fukuda R, Gerri C, Kikhi K, Giraldez A, Stainier DYR. 2019. Genetic compensation is triggered by mutant mRNA degradation. Nature. DOI: 10.1101/328153.

Gallati, M.M., and Talbot, J.C. 2020. Snu13 genes are essential for embryonic development past early segmentation stages. ZebraShare, ZFIN abstract: ZDB-PUB-200604-17

Garcia CK, Wilund K, Arca M, Zuliani G, Fellin R, Maioli M, Calandra S, Bertolini S, Cossu F, Grishin N, Barnes R, Cohen JC, Hobbs HH. 2001. Autosomal recessive hypercholesterolemia caused by mutations in a putative LDL receptor adaptor protein. Science (New York, N.Y.) 292:1394-1398. DOI: 10.1126/science.1060458.

Hakimi M-A, Dong Y, Lane WS, Speicher DW, Shiekhattar R. 2003. A candidate X-linked mental retardation gene is a component of a new family of histone deacetylase-containing complexes. The Journal of Biological Chemistry 278:7234-7239. DOI: 10.1074/jbc.M208992200.

Harris TW, Arnaboldi V, Cain S, Chan J, Chen WJ, Cho J, Davis P, Gao S, Grove CA, Kishore R, Lee RYN, Muller H-M, Nakamura C, Nuin P, Paulini M, Raciti D, Rodgers FH, Russell M, Schindelman G, Auken KV, Wang Q, Williams G, Wright AJ, Yook K, Howe KL, Sched1 T, Stein L, Sternberg PW. 2020. WormBase: a modern Model Organism Information Resource. Nucleic Acids Research 48:D762-D767. DOI: 10.1093/nar/gkz920.

Hernández-Martínez R, Ramkumar N, Anderson KV. 2019. p120-catenin regulates WNT signaling and EMT in the mouse embryo. Proceedings of the National Academy of Sciences of the United States of America 116:16872-16881. DOI: 10.1073/pnas.1902843116.

Howe DG, Bradford YM, Eagle A, Fashena D, Frazer K, Kalita P, Mani P, Martin R, Moxon ST, Paddock H, Pich C, Ramachandran S, Ruzicka L, Schaper K, Shao X, Singer A, Toro S, Van Slyke C, Westerfield M. 2016. A scientist's guide for submitting data to ZFIN. In: Methods in Cell Biology. Elsevier, 451-481. DOI: 10.1016/bs.mcb.2016.04.010.

Hsu CL, Muerdter CP, Knickerbocker AD, Walsh RM, Zepeda-Rivera MA, Depner KH, Sangesland M, Cisneros TB, Kim JY, Sanchez-Vazquez P, Cherezova L, Regan RD, Bahrami NM, Gray EA, Chan AY, Chen T, Rao MY, Hille MB. 2012. Cdc42 GTPase and Rac1 GTPase act downstream of p120 catenin and require GTP exchange during gastrulation of zebrafish mesoderm. Developmental Dynamics 241:1545-1561. DOI: https://doi.org/10.1002/dvdy.23847.

Jao L-E, Wente SR, Chen W. 2013. Efficient multiplex biallelic zebrafish genome editing using a CRISPR nuclease system. Proceedings of the National Academy of Sciences 110:13904-13909. DOI: 10.1073/pnas.1308335110. 
513 Johnson AN, Mokalled MH, Valera JM, Poss KD, Olson EN. 2013. Post-transcriptional

514

515

516

517

518

519

520

521

522

523

524

525

526

527

528

529

530

531

532

533

534

535

536

537

538

539

540

541

542

543

544

545

546

547

548

549

550

regulation of myotube elongation and myogenesis by Hoi Polloi. Development 140:36453656. DOI: $10.1242 / \mathrm{dev} .095596$.

Kettleborough RNW, Busch-Nentwich EM, Harvey SA, Dooley CM, de Bruijn E, van Eeden F, Sealy I, White RJ, Herd C, Nijman IJ, Fényes F, Mehroke S, Scahill C, Gibbons R, Wali N, Carruthers S, Hall A, Yen J, Cuppen E, Stemple DL. 2013. A systematic genome-wide analysis of zebrafish protein-coding gene function. Nature 496:494-497. DOI: 10.1038/nature11992.

Kim H-G, Kim H-T, Leach NT, Lan F, Ullmann R, Silahtaroglu A, Kurth I, Nowka A, Seong IS, Shen Y, Talkowski ME, Ruderfer D, Lee J-H, Glotzbach C, Ha K, Kjaergaard S, Levin AV, Romeike BF, Kleefstra T, Bartsch O, Elsea SH, Jabs EW, MacDonald ME, Harris DJ, Quade BJ, Ropers H-H, Shaffer LG, Kutsche K, Layman LC, Tommerup N, Kalscheuer VM, Shi Y, Morton CC, Kim C-H, Gusella JF. 2012. Translocations disrupting PHF21A in the Potocki-Shaffer-syndrome region are associated with intellectual disability and craniofacial anomalies. American Journal of Human Genetics 91:56-72. DOI: 10.1016/j.ajhg.2012.05.005.

Kim H-G, Rosenfeld JA, Scott DA, Bénédicte G, Labonne JD, Brown J, McGuire M, Mahida S, Naidu S, Gutierrez J, Lesca G, des Portes V, Bruel A-L, Sorlin A, Xia F, Capri Y, Muller E, McKnight D, Torti E, Rüschendorf F, Hummel O, Islam Z, Kolatkar PR, Layman LC, Ryu D, Kong I-K, Madan-Khetarpal S, Kim C-H. 2019. Disruption of PHF21A causes syndromic intellectual disability with craniofacial anomalies, epilepsy, hypotonia, and neurobehavioral problems including autism. Molecular Autism 10:35. DOI: 10.1186/s13229-019-0286-0.

Kimmel CB, Ballard WW, Kimmel SR, Ullmann B, Schilling TF. 1995. Stages of embryonic development of the zebrafish. Developmental dynamics 203:253-310.

Kok FO, Shin M, Ni C-W, Gupta A, Grosse AS, van Impel A, Kirchmaier BC, Peterson-Maduro J, Kourkoulis G, Male I, DeSantis DF, Sheppard-Tindell S, Ebarasi L, Betsholtz C, Schulte-Merker S, Wolfe SA, Lawson ND. 2015. Reverse Genetic Screening Reveals Poor Correlation between Morpholino-Induced and Mutant Phenotypes in Zebrafish. Developmental Cell 32:97-108. DOI: 10.1016/j.devcel.2014.11.018.

Lan F, Collins RE, De Cegli R, Alpatov R, Horton JR, Shi X, Gozani O, Cheng X, Shi Y. 2007. Recognition of unmethylated histone $\mathrm{H} 3$ lysine 4 links BHC80 to LSD1-mediated gene repression. Nature 448:718-722. DOI: 10.1038/nature06034.

Mishoe, L.N., and DeLaurier, A. 2020. A frameshift mutation in the PHD Finger Protein 21A repressor of transcription phf21aa. ZebraShare, ZFIN Abstract: ZDB-PUB-190605-16

Moens CB, Donn TM, Wolf-Saxon ER, Ma TP. 2008. Reverse genetics in zebrafish by TILLING. Briefings in Functional Genomics \& Proteomics 7:454-459. DOI: 10.1093/bfgp/eln046.

Peerj reviewing PDF | (2020:08:52244:1:1:NEW 7 Jan 2021) 
551

552

553

554

555

556

557

558

559

560

561

562

563

564

565

566

567

568

569

570

571

572

573

574

575

576

577

578

579

580

581

582

583

584

585

586

587

588

589

Oruganti S vdya, Zhang Y, Li H. 2005. Structural comparison of yeast snoRNP and spliceosomal protein Snu13p with its homologs. Biochemical and Biophysical Research Communications 333:550-554. DOI: 10.1016/j.bbrc.2005.05.141.

Papatheodorou I, Fonseca NA, Keays M, Tang YA, Barrera E, Bazant W, Burke M, Füllgrabe A, Fuentes AM-P, George N, Huerta L, Koskinen S, Mohammed S, Geniza M, Preece J, Jaiswal P, Jarnuczak AF, Huber W, Stegle O, Vizcaino JA, Brazma A, Petryszak R. 2018. Expression Atlas: gene and protein expression across multiple studies and organisms. Nucleic Acids Research 46:D246-D251. DOI: 10.1093/nar/gkx1158.

Pieters T, Goossens S, Haenebalcke L, Andries V, Stryjewska A, De Rycke R, Lemeire K, Hochepied T, Huylebroeck D, Berx G, Stemmler MP, Wirth D, Haigh JJ, van Hengel J, van Roy F. 2016. p120 Catenin-Mediated Stabilization of E-Cadherin Is Essential for Primitive Endoderm Specification. PLoS genetics 12:e1006243. DOI: 10.1371/journal.pgen.1006243.

Rafferty SA, Quinn TA. 2018. A beginner's guide to understanding and implementing the genetic modification of zebrafish. Progress in Biophysics and Molecular Biology 138:319. DOI: 10.1016/j.pbiomolbio.2018.07.005.

Robu ME, Larson JD, Nasevicius A, Beiraghi S, Brenner C, Farber SA, Ekker SC. 2007. p53 Activation by Knockdown Technologies. PLOS Genetics 3:e78. DOI: 10.1371/journal.pgen.0030078.

Rossi A, Kontarakis Z, Gerri C, Nolte H, Hölper S, Krüger M, Stainier DYR. 2015. Genetic compensation induced by deleterious mutations but not gene knockdowns. Nature 524:230-233. DOI: 10.1038/nature14580.

Rothé B, Back R, Quinternet M, Bizarro J, Robert M-C, Blaud M, Romier C, Manival X, Charpentier B, Bertrand E, Branlant C. 2014. Characterization of the interaction between protein Snu13p/15.5K and the Rsa1p/NUFIP factor and demonstration of its functional importance for snoRNP assembly. Nucleic Acids Research 42:2015-2036. DOI: 10.1093/nar/gkt1091.

Schindelin J, Arganda-Carreras I, Frise E, Kaynig V, Longair M, Pietzsch T, Preibisch S, Rueden C, Saalfeld S, Schmid B, Tinevez J-Y, White DJ, Hartenstein V, Eliceiri K, Tomancak P, Cardona A. 2012. Fiji: an open-source platform for biological-image analysis. Nature Methods 9:676-682. DOI: 10.1038/nmeth.2019.

Schizophrenia Working Group of the Psychiatric Genomics Consortium. 2014. Biological insights from 108 schizophrenia-associated genetic loci. Nature 511:421-427. DOI: 10.1038/nature13595.

Shi Y, Lan F, Matson C, Mulligan P, Whetstine JR, Cole PA, Casero RA, Shi Y. 2004. Histone demethylation mediated by the nuclear amine oxidase homolog LSD1. Cell 119:941-953. DOI: $10.1016 /$ j.cell.2004.12.012.

Stainier DYR, Kontarakis Z, Rossi A. 2015. Making Sense of Anti-Sense Data. Developmental Cell 32:7-8. DOI: 10.1016/j.devcel.2014.12.012. 
590 Stainier DY, Raz E, Lawson ND, Ekker SC, Burdine RD, Eisen JS, Ingham PW, Schulte-Merker

591

592

593

594

595

596

597

598

599

600

601

602

603

604

605

606

607

608

609

610

611

612

613

614

615

616

617

618

619

620

621

622

623

624

625

626

627

628

S, Yelon D, Weinstein BM. 2017. Guidelines for morpholino use in zebrafish. PLoS genetics 13:e1007000.

Stevens SW, Barta I, Ge HY, Moore RE, Young MK, Lee TD, Abelson J. 2001. Biochemical and genetic analyses of the U5, U6, and U4/U6 x U5 small nuclear ribonucleoproteins from Saccharomyces cerevisiae. RNA (New York, N.Y.) 7:1543-1553.

Talbot JC, Amacher SL. 2014. A streamlined CRISPR pipeline to reliably generate zebrafish frameshifting alleles. Zebrafish 11:583-585. DOI: 10.1089/zeb.2014.1047.

Tessadori F, de Bakker DEM, Barske L, Nelson N, Algra HA, Willekers S, Nichols JT, Crump JG, Bakkers J. 2020. Zebrafish prrxla mutants have normal hearts. Nature 585:E14-E16. DOI: $10.1038 / \mathrm{s} 41586-020-2674-1$

Thurmond J, Goodman JL, Strelets VB, Attrill H, Gramates LS, Marygold SJ, Matthews BB, Millburn G, Antonazzo G, Trovisco V, Kaufman TC, Calvi BR, Perrimon N, Gelbart SR, Agapite J, Broll K, Crosby L, Santos G dos, Emmert D, Gramates LS, Falls K, Jenkins V, Matthews B, Sutherland C, Tabone C, Zhou P, Zytkovicz M, Brown N, Antonazzo G, Attrill H, Garapati P, Holmes A, Larkin A, Marygold S, Millburn G, Pilgrim C, Trovisco V, Urbano P, Kaufman T, Calvi B, Czoch B, Goodman J, Strelets V, Thurmond J, Cripps R, Baker P. 2019. FlyBase 2.0: the next generation. Nucleic Acids Research 47:D759D765. DOI: 10.1093/nar/gky1003.

Thyme, S.B., and Carte, A. 2020. A CRISPR Mutagenesis Screen of Ctnnd1. ZebraShare, ZFIN Abstract: ZDB-PUB-200621-10

Tunovic S, Barkovich J, Sherr EH, Slavotinek AM. 2014. De novo ANKRD11 and KDM1A gene mutations in a male with features of KBG syndrome and Kabuki syndrome. American Journal of Medical Genetics. Part A 164A:1744-1749. DOI: 10.1002/ajmg.a.36450.

Turner TN, Sharma K, Oh EC, Liu YP, Collins RL, Sosa MX, Auer DR, Brand H, Sanders SJ, Moreno-De-Luca D, Pihur V, Plona T, Pike K, Soppet DR, Smith MW, Cheung SW, Martin CL, State MW, Talkowski ME, Cook E, Huganir R, Katsanis N, Chakravarti A. 2015. Loss of $\delta$-catenin function in severe autism. Nature 520:51-56. DOI: 10.1038 /nature14186.

Van Slyke CE, Bradford YM, Howe DG, Fashena DS, Ramachandran S, Ruzicka L. 2018. Using ZFIN: Data Types, Organization, and Retrieval. Methods in molecular biology (Clifton, N.J.) 1757:307-347. DOI: 10.1007/978-1-4939-7737-6_11.

Varshney GK, Zhang S, Pei W, Adomako-Ankomah A, Fohtung J, Schaffer K, Carrington B, Maskeri A, Slevin C, Wolfsberg T, Ledin J, Sood R, Burgess SM. 2016. CRISPRz: a database of zebrafish validated sgRNAs. Nucleic Acids Research 44:D822-826. DOI: 10.1093/nar/gkv998.

Walker M, Kimmel C. 2007. A two-color acid-free cartilage and bone stain for zebrafish larvae. Biotechnic \& Histochemistry 82:23-28. DOI: 10.1080/10520290701333558.

Peer) reviewing PDF | (2020:08:52244:1:1:NEW 7 Jan 2021) 
629 Westerfield M. 2007. The Zebrafish Book: A guide for the laboratory use of zebrafish (Danio

630

631

632

633

634

635

636

637

638

639

640

641

642

643

644

645

646

647 rerio). Eugene: University of Oregon Press.

Williams J, Boin NG, Valera JM, Johnson AN. 2015. Noncanonical roles for Tropomyosin during myogenesis. Development (Cambridge, England) 142:3440-3452. DOI: 10.1242/dev.117051.

Winzeler EA, Shoemaker DD, Astromoff A, Liang H, Anderson K, Andre B, Bangham R, Benito R, Boeke JD, Bussey H, Chu AM, Connelly C, Davis K, Dietrich F, Dow SW, El Bakkoury M, Foury F, Friend SH, Gentalen E, Giaever G, Hegemann JH, Jones T, Laub M, Liao H, Liebundguth N, Lockhart DJ, Lucau-Danila A, Lussier M, M'Rabet N, Menard P, Mittmann M, Pai C, Rebischung C, Revuelta JL, Riles L, Roberts CJ, RossMacDonald P, Scherens B, Snyder M, Sookhai-Mahadeo S, Storms RK, Véronneau S, Voet M, Volckaert G, Ward TR, Wysocki R, Yen GS, Yu K, Zimmermann K, Philippsen P, Johnston M, Davis RW. 1999. Functional characterization of the S. cerevisiae genome by gene deletion and parallel analysis. Science (New York, N.Y.) 285:901-906. DOI: 10.1126/science.285.5429.901.

Yu HH, Dohn MR, Markham NO, Coffey RJ, Reynolds AB. 2016. p120-catenin controls contractility along the vertical axis of epithelial lateral membranes. Journal of Cell Science 129:80-94. DOI: 10.1242/jcs.177550. 


\section{Table 1 (on next page)}

gRNA targets used for CRISPR and genotyping primer sequences (5'-3').

These mutants were generated in three separate labs so they used different mutagenesis and genotyping protocols. Three gRNAs were co-injected for ctnnd1. 


\begin{tabular}{|c|c|c|c|c|}
\hline Originating lab & Gene & gRNA target(s) & Forward Genotyping Primer & Reverse genotyping primer \\
\hline \multirow[t]{2}{*}{ DeLaurier } & \multirow[t]{2}{*}{ phf21aa } & \multirow[t]{2}{*}{ GTGAGGCTAGCAGCAGGCAG } & $\begin{array}{l}\text { T7 assay: } \\
\text { GATTTCCTTGCCACTAGCAC }\end{array}$ & $\begin{array}{l}\text { T7 assay: } \\
\text { CCATTAAGAAGCAGCACAGG }\end{array}$ \\
\hline & & & $\begin{array}{l}\text { Traditional genotyping: } \\
\text { AGAATACTGTTGGCСTCСTG }\end{array}$ & $\begin{array}{l}\text { Traditional genotyping: } \\
\text { CCATTAAGAAGCAGCACAGG }\end{array}$ \\
\hline DeLaurier & kdm1a & GGCTCCTCCTCTTCGTCAGG & $\begin{array}{l}\text { T7 assay/ Traditional genotyping: } \\
\text { AAGGAGAAGCCTCTGTCATC }\end{array}$ & $\begin{array}{l}\text { T7 assay/ Traditional genotyping: } \\
\text { GAGATGTTTACCTTTGCCCG }\end{array}$ \\
\hline Thyme & ctnnd1 & $\begin{array}{l}\text { GGTCCAACTGAGGTCGGCTG, } \\
\text { CCTCCAGGCCATAGGGCTCT, } \\
\text { CTGATCGTCCTCCAGGCCAT }\end{array}$ & $\begin{array}{l}\text { Traditional genotyping: } \\
\text { ATGGCTACCGCACGCTGGAC }\end{array}$ & $\begin{array}{l}\text { Traditional genotyping: } \\
\text { GTGTGGATGTGCCAACCGGGG }\end{array}$ \\
\hline \multirow[t]{2}{*}{ Talbot } & \multirow[t]{2}{*}{ snu13a } & \multirow[t]{2}{*}{ GAACCCTAAAGCGTACCCTC } & $\begin{array}{l}\text { HRMA genotyping: } \\
\text { GACTGATCAAGTGCTGTTCTCC }\end{array}$ & $\begin{array}{l}\text { HRMA genotyping: } \\
\text { ATCCAGGATGGTTTTGCTGAGG }\end{array}$ \\
\hline & & & $\begin{array}{l}\text { DNA sequencing: } \\
\text { TGGCTAATCTTTATGGTTCAGG }\end{array}$ & $\begin{array}{l}\text { DNA sequencing: } \\
\text { CTTCGTTGGCCCCTTTC }\end{array}$ \\
\hline \multirow[t]{2}{*}{ Talbot } & \multirow[t]{2}{*}{ snu13b } & \multirow[t]{2}{*}{ GAACCCTAAAGCCTATCCTC } & $\begin{array}{l}\text { HRMA genotyping: } \\
\text { GTCTGTGGTTTTACTCAGACTG }\end{array}$ & $\begin{array}{l}\text { HRMA genotyping: } \\
\text { CCCCTTTTCTCAGCTGTTTG }\end{array}$ \\
\hline & & & $\begin{array}{l}\text { DNA sequencing: } \\
\text { TGCTAACCGGATGATAAGAG }\end{array}$ & $\begin{array}{l}\text { DNA sequencing: } \\
\text { CGAGTTATTCACCTTCATTGG }\end{array}$ \\
\hline
\end{tabular}

3 


\section{Table 2 (on next page)}

Web addresses for the ZebraShare abstracts for alleles used in case studies. 
1

\begin{tabular}{|c|c|}
\hline Allele(s) & ZebraShare abstract page \\
\hline phf21aa alk4 & http://zfin.org/ZDB-PUB-190605-16 \\
\hline$k d m 1 a^{a l k 5}$ & http://zfin.org/ZDB-PUB-200515-15 \\
\hline ctnnd1 $1^{\text {uab302 }}$ & http://zfin.org/ZDB-PUB-200621-10 \\
\hline snu13a, snu13b & http://zfin.org/ZDB-PUB-200604-17 \\
\hline
\end{tabular}

2

3 
Figure 1

Publicizing a mutant on ZebraShare in 5 steps. 


\section{Step 1:}

Follow links to ZebraShare from zfin.org

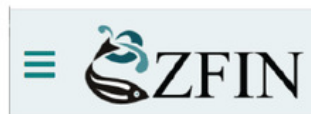

Sign In

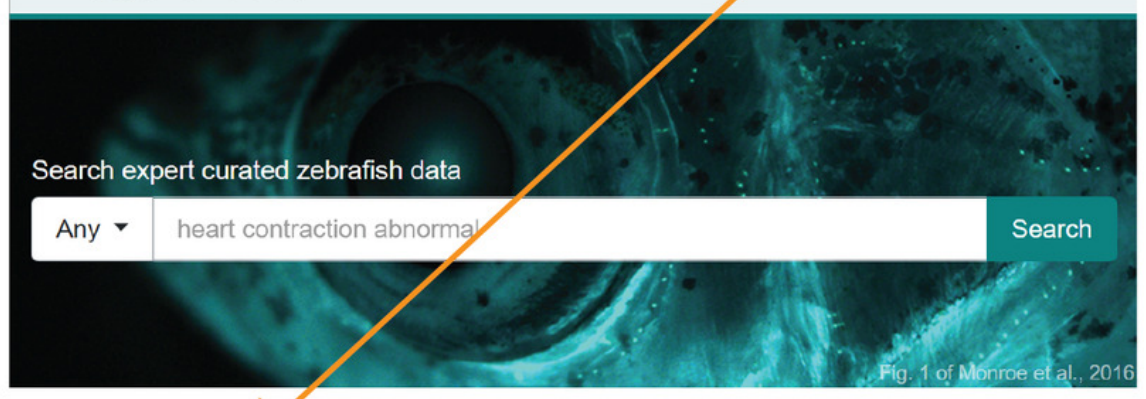

Submit Data

Guidelines and forms to sulmit data to ZFIN

\section{ZebraShare}

ZebraShare is intended to help establish fruitful collaborations by sharing mutant fish lines, and information about these mutants, particularly when authors do not otherwise see a clear path to publication.

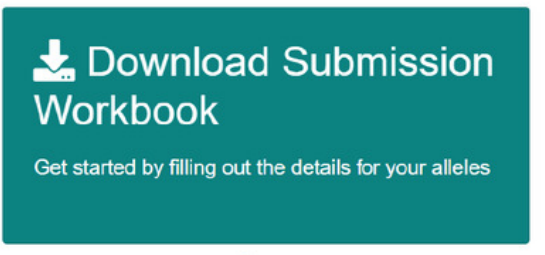

ㄴ. Submit Completed Workbook

ZFIN curators will process your submission as part of their high priority literature curation workflow

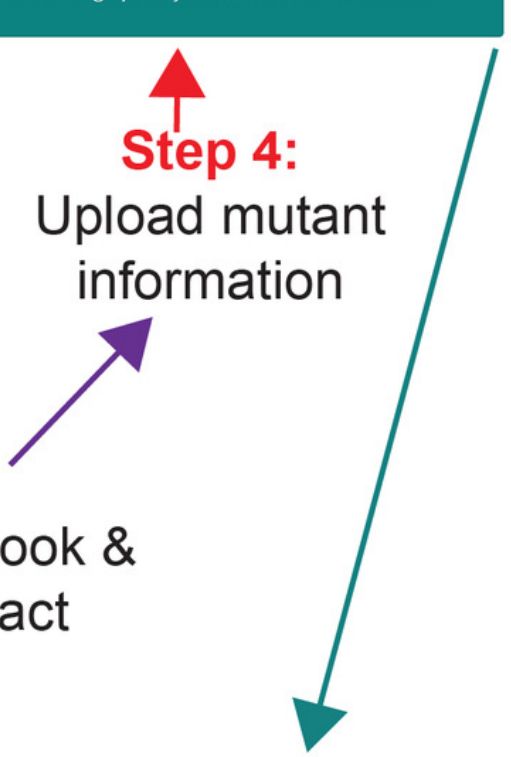

\section{Step 5: ZFIN curates your data and publicizes it on their website}


Figure 2

Example of how to determine DNA coordinates for a simple deletion allele, phf21aa alk4.

(A) Align the WT and mutant sequence. (B) Blast the aligned WT sequence and determine the base numbers altered in the mutant. (C) Transfer these coordinates to the ZebraShare submission workbook. Descriptions become more complex for combined insertion/deletions alleles (InDels) and for alleles with multiple mutation sites due to use of multiple guide RNAs.

\section{A) Generate a WT/MUT sequence alignment WT 5'-TCGTCGTCCGTCTCCGCAGACACAGAC-3' MUT 5' 5 -TCGTCGTCCG------AGACACAGAC-3'}

\section{B) BLAST using WT, select bases to determine coordinates changed in the mutant}

Deleted

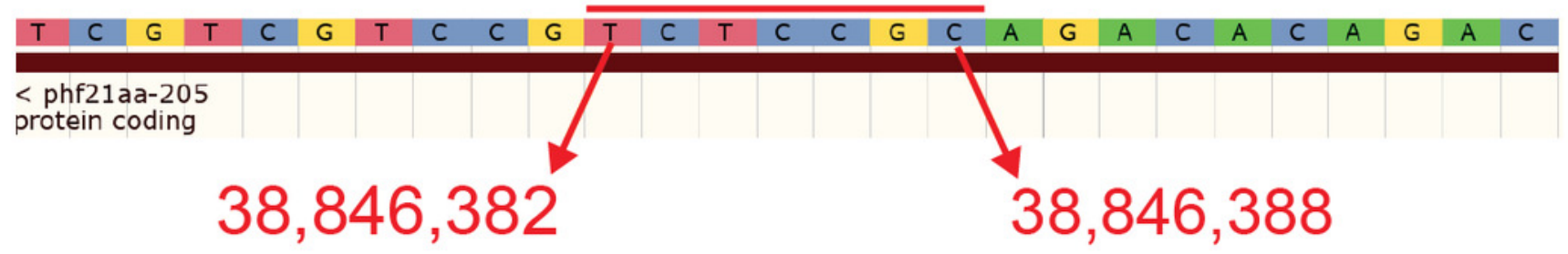

\section{C) Describe these coordinates in the workbook} phf21aa alk5 is a 7 bp deletion GRCz11 Chr:7 38,846,382-38,846,388 


\section{Figure 3}

Example of a mutant, phf21aa aik4, publicized via ZebraShare.

(A) The allele description page shows information that helps researchers interpret the mutant. (B) The abstract page gives an overview of phenotypic characterization. (C) The figure associated with the abstract shows pertinent phenotypic details. For phf21aa ${ }^{\text {aik4 }}$, the mutants appeared normal, save for a mild rotation of the ceratohyal cartilage (red arrow). Fish larvae are stained with alcian blue (cartilage) and alizarin red (bone) to reveal skeletal shape. Scale bar in whole mount lateral views $=100$ microns, in pharyngeal skeleton and neurocranium flat mounts scale $b a r=200$ microns. 


\section{A) phf21aaaik4 allele page}

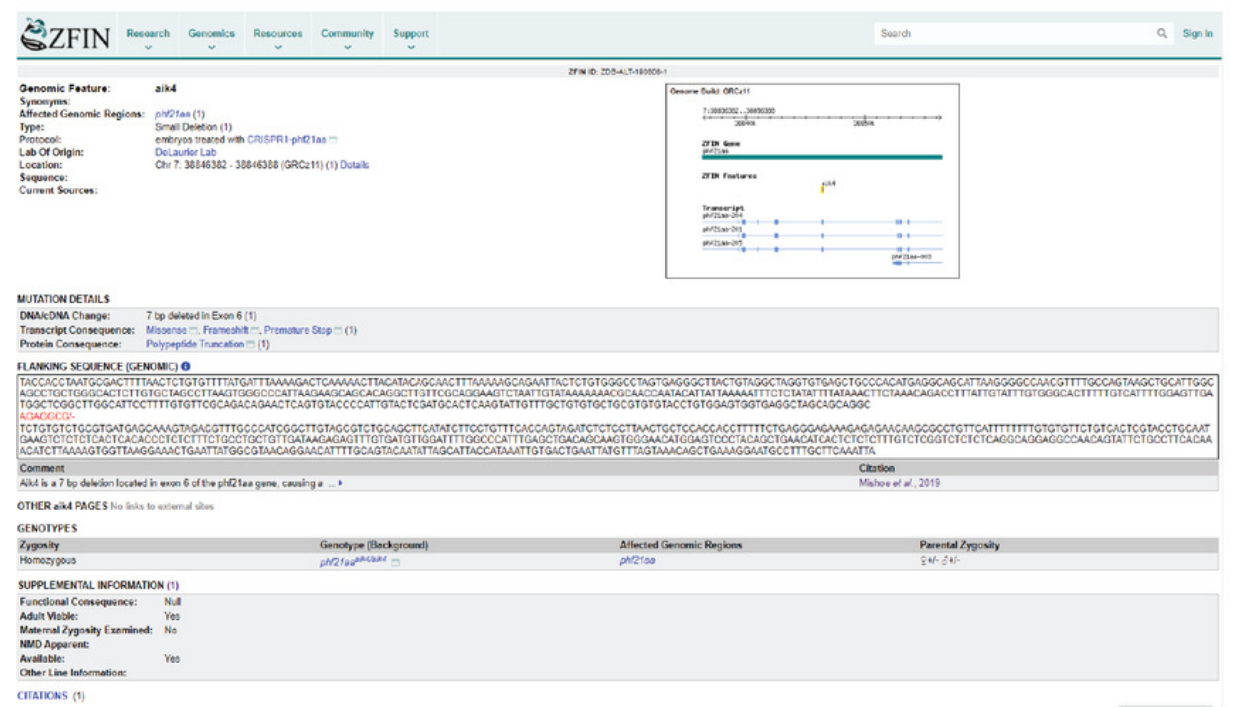

\section{B) phf21aaaik4 abstract page}

ZFIN ID: ZDB-PUB-190605-16

A frameshift mutation in the PHD Finger Protein 21A repressor of transcription phf21aa

$\begin{array}{ll}\text { Date: } & 2019 \\ \text { Source: } & \text { ZebraShare } \\ \text { Registered Authors: } & \text { DeLaurier, Ap } \\ \text { Keywords: } & \text { none } \\ \text { MeSH Terms: } & \text { none } \\ \text { PubMed: } & \text { none } \\ \text { FIGURES (i) } & \\ \text { ABSTRACT } & \\ \text { CRISPR-Cas9 mutagenesis was use } \\ \text { missense and a premature stop codo } \\ \text { appearance although a mild rotation } \\ \text { Mutants are viable as adults. } \\ \text { ADDITIONAL INFORMATION } \\ \text { - Genes / Markers (1) } \\ \text { - CRISPR (1) } \\ \text { - Phenotype Data } \\ \text { - Mutations and Transgenics (1) } \\ \text { - Fish (1) }\end{array}$
Mishoe, L.N., and DeLaurier, A.

\section{C) Figure associated with abstract}

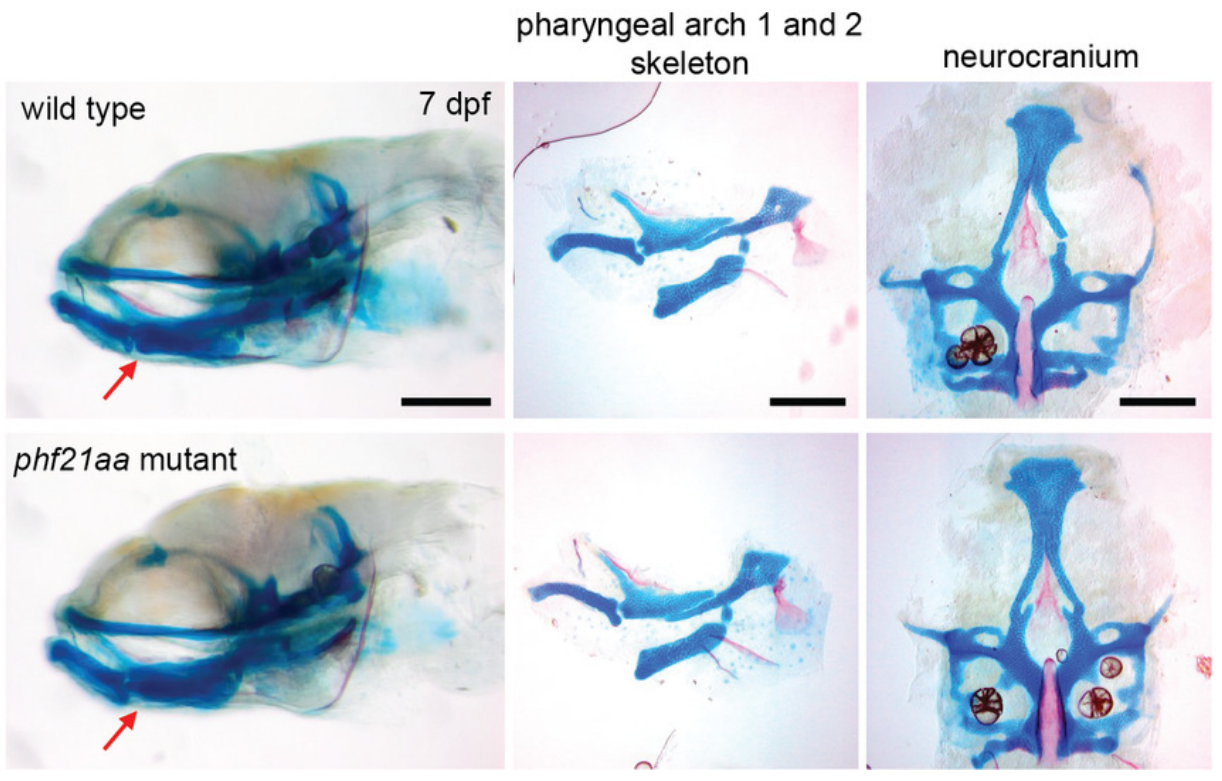




\section{Figure 4}

Skeletal structure is normal in kdmla maternal zygotic mutants.

Wild-type larvae (A-C) compared with kdmla maternal zygotic mutant larvae (D-F). A and

D: Whole mount specimens, lateral view of head skeleton, B and E: flat mount pharyngeal skeleton, pharyngeal arches 1 and 2, lateral view, C and F: flat mount neurocranium, ventral view. Fish larvae are stained as described in Figure 3. Scale bar $=200$ microns.

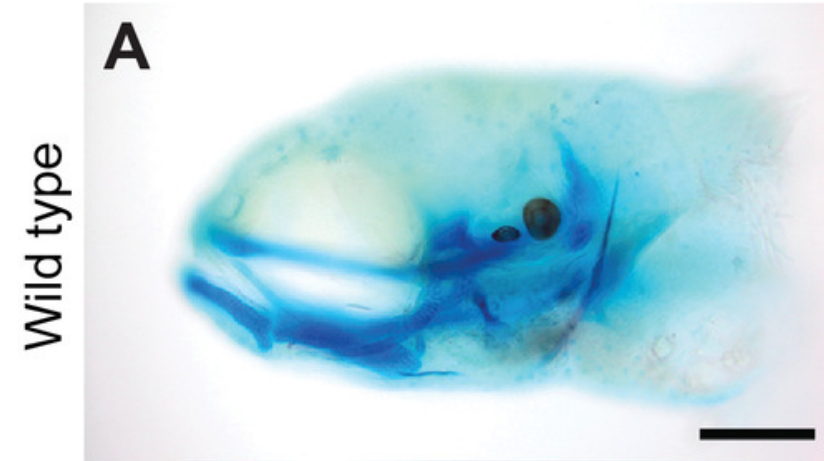

B

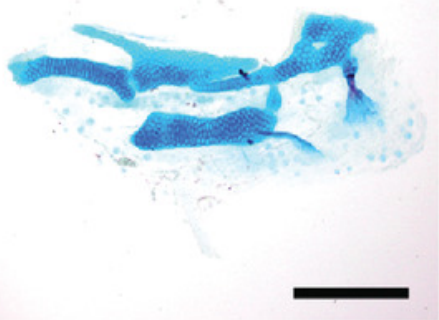

E
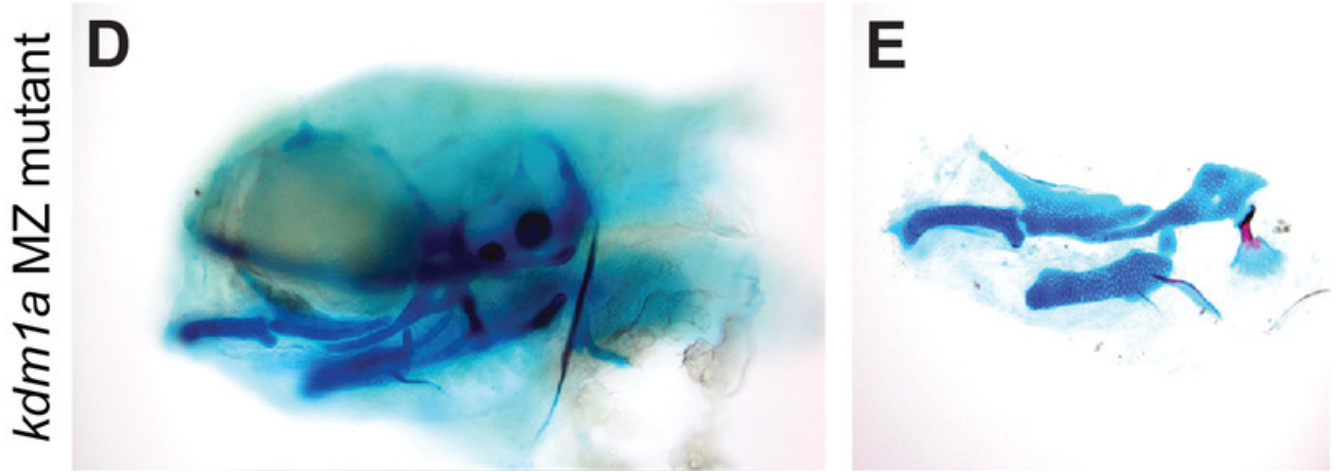

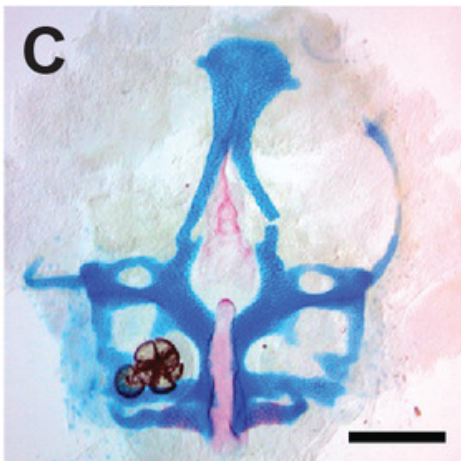

F.

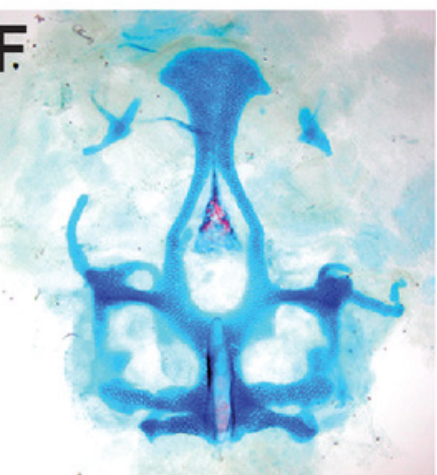




\section{Figure 5}

Embryonic disintegration in ctnnd1 mutants.

(A, B) Frames from time-lapse imaging (Supplementary Movie 1) illustrate disintegrating phenotype of ctnnd1 mutants. Asterisk(s) mark two of the embryos that disintegrated during the time-lapse recording. (C) DAPI staining of fixed ctnnd1 mutant embryos reveals that cells with intact nuclei dissociate from the embryo. (D-F) Phenotypes of ctnnd1 sibling embryos at the $\sim 6$-somite stage. The homozygous mutant $(F)$ has disintegrated, the heterozygous mutant (E) displays clumps of cells along the dorsal surface, and the wild-type embryo appears normal (D). The solid arrow marks a clump of cells dorsal to the midbrain and the open arrowhead marks a clump of cells dorsal to the hindbrain in the heterozygote.
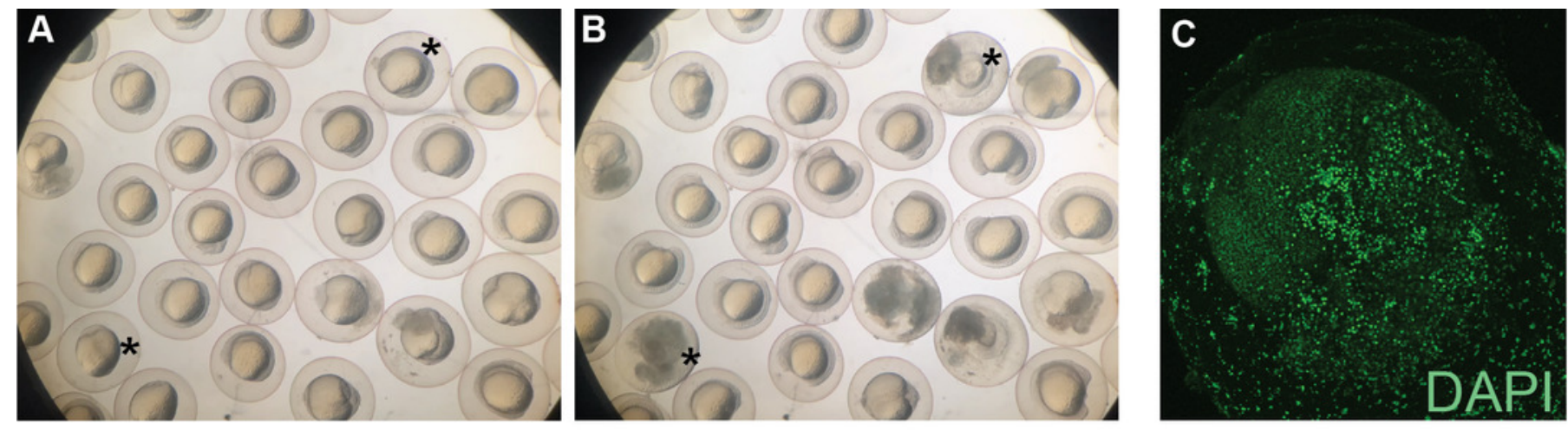

D

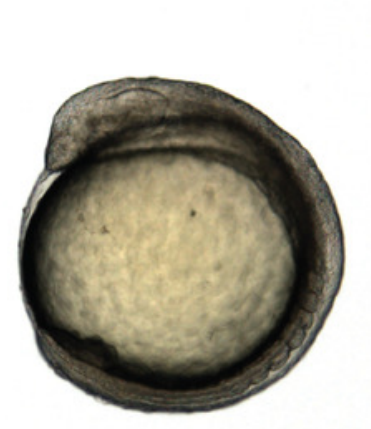

wild type
E

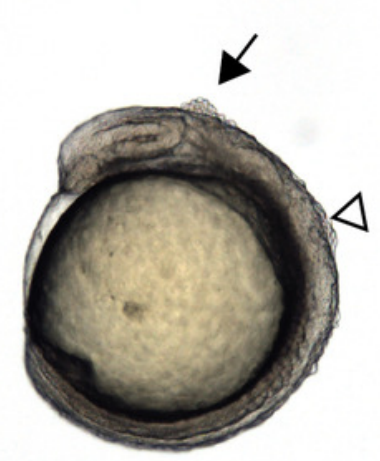

ctnnd $1^{+/-}$

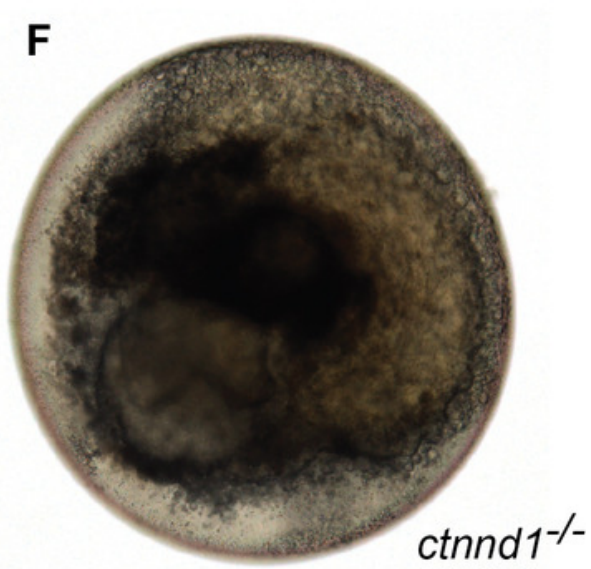




\section{Figure 6}

Embryonic development arrests in snu13a;snu13b double mutants.

(A) Normal sibling and (B) snu13a;snu13b double mutant at $24 \mathrm{hpf}$. Tail region is outlined in orange, head in blue. The shown double mutant was confirmed to be homozygous by Sanger sequencing. Scale bar is $1 \mathrm{~mm}$.

\section{$\begin{array}{ll}\text { A) Normal sibling } & \text { B) snu13a } a^{-/ ;} ; s n u 13 b^{-/-}\end{array}$}

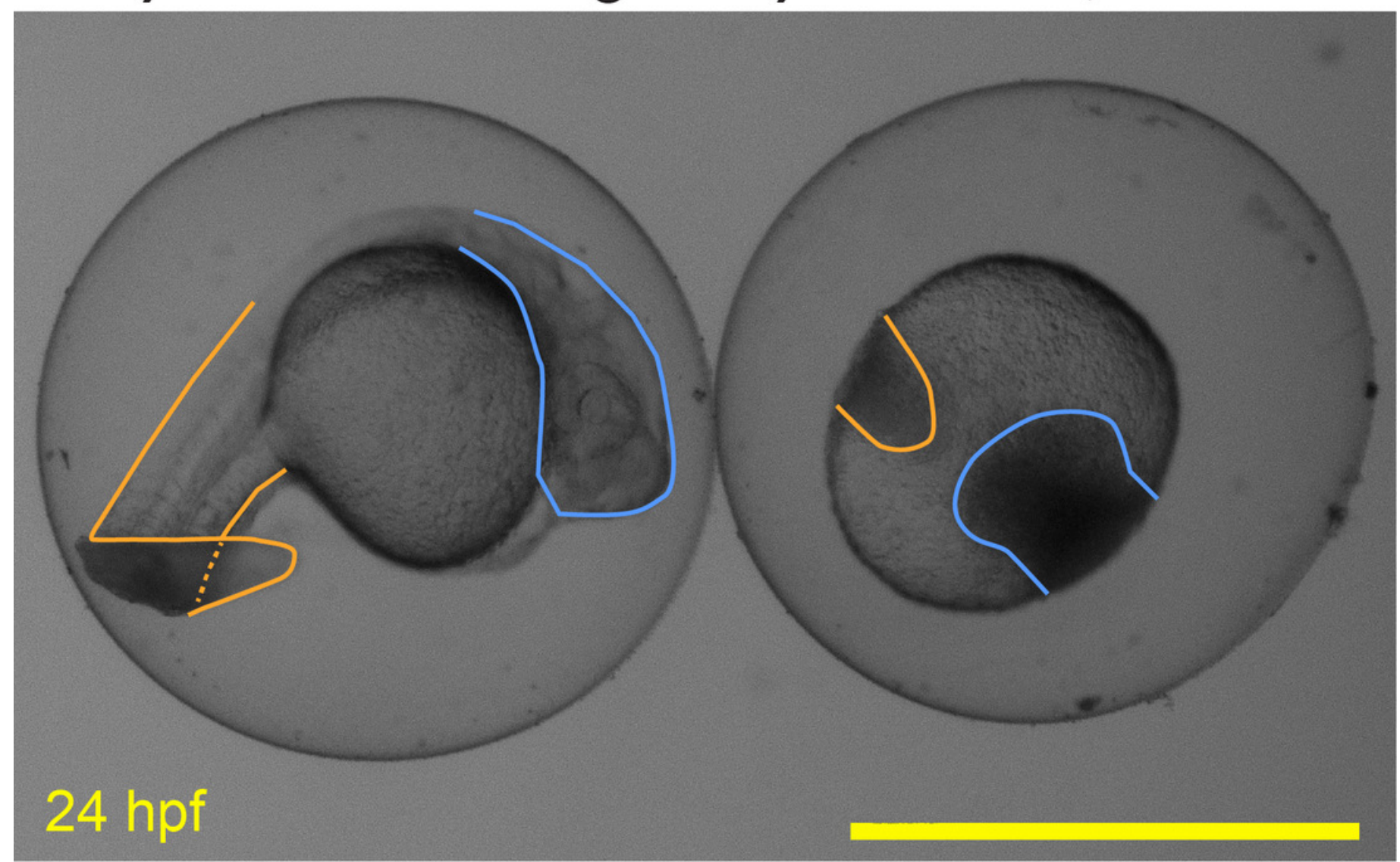


Figure 7

A decision tree on whether to publicize findings in ZebraShare.

A) A ZebraShare submission immediately disseminates your information to the scientific community and also can serve as a pathway to journal publication. B) Comparison of correct and misplaced ZebraShare submissions, with solutions for incorrect uses. 


\section{A) ZebraShare is a pathway to publication}

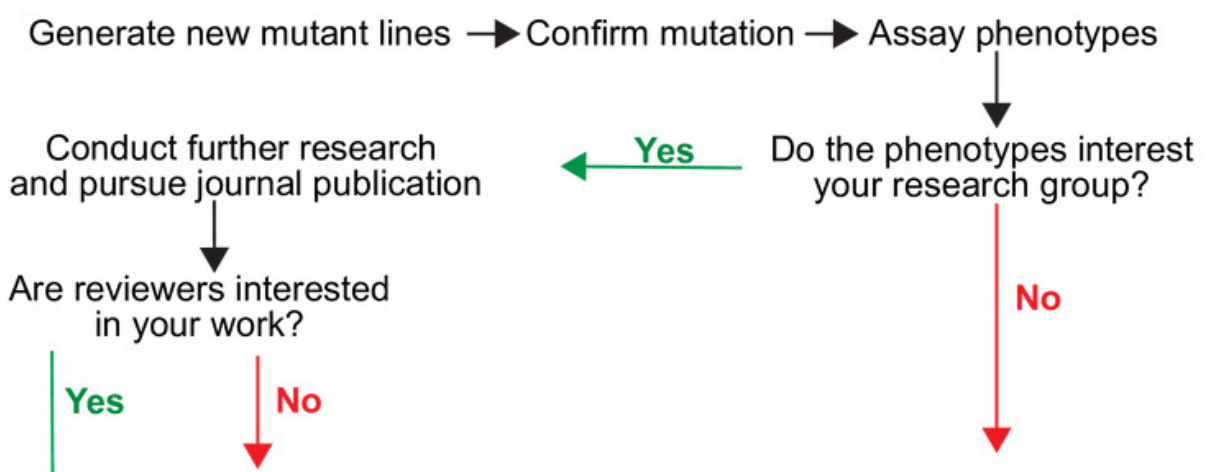

Do you see a new path to journal publication?<smiles>C1CC([As]2CCC2)C1</smiles>

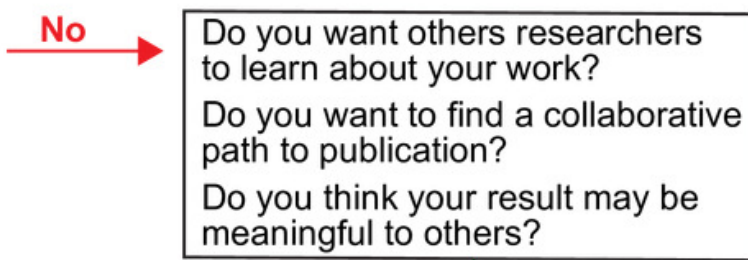

Publish your findings in a journal
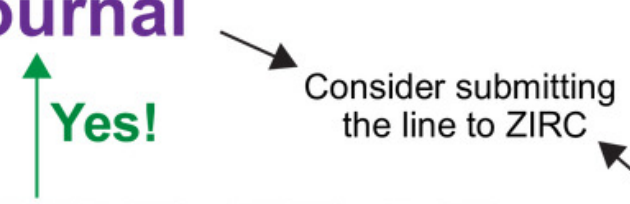

After submitting to ZebraShare did you -make a new discovery? -collaboratively share your mutants? -find a path to publication?<smiles>[CH][CH]</smiles>
the line to ZIRC

\section{Your findings are now searchable in ZFIN}

\section{B)}

ZebraShare IS for:

$\checkmark$ Publicizing verified alleles

$\checkmark \begin{aligned} & \text { Reporting confirmation steps } \\ & \text { on the unpublished alleles }\end{aligned}$

$\sqrt{\text { Publicizing a few alleles }}$

Unpublished phenotypes

Establishing collaborations

\section{ZebraShare is NOT for:}

X Publicizing CRISPR guide RNA

Do this on CRISPRz

$X$ Publicizing mutants that have not even been sequenced Verify before submitting

X Reporting a large-scale screen For this, contact ZFIN directly

$X$ Re-reporting published mutants ZFIN will curate published mutants automatically

X Discouraging other researchers 